\title{
High Incidence of Angina pectoris in Patients Treated with 5-Fluorouracil
}

\author{
A Planned Surveillance Study with 102 Patients
}

\author{
Annette Wacker ${ }^{a}$ Christian Lersch $^{c}$ Ute Scherpinski ${ }^{b}$ Laurence Reindl $^{d}$ \\ Melchior Seyfarth ${ }^{\text {a }}$
}

al. Medizinische Klinik und Deutsches Herzzentrum, b Neurologische Klinik, cll. Medizinische Klinik, Klinikum rechts der Isar, Technische Universität München, dDr. v. Haunersches Kinderspital, Ludwig-Maximilians-Universität München, München, Deutschland

\section{Key Words}

5-Fluorouracil · Vasospasm · Angina pectoris

\begin{abstract}
Objective: Angina pectoris, arrhythmic sudden death and myocardial infarction, all these cardiac events have occasionally been reported during 5-fluorouracil (5-FU) chemotherapy. Underlying mechanisms leading to these events are unknown; damage to the myocytes or vasospasms have been discussed. Methods: 102 consecutive and unselected patients were monitored with 12-lead ECG, echocardiography and radionuclide ventriculography prior to the first cycle of 5-FU chemotherapy and 3 months from baseline. Results: $19 \%$ of the patients developed reversible symptoms of angina pectoris during treatment which lasted up to $12 \mathrm{~h}$ after cessation of the infusion. Most of the 19 patients showed corresponding ECG changes. 6 out of the 19 patients with severe angina pectoris had subsequent coronary angiography. In none of these patients the coronary angiography showed coronary artery disease, but it showed low ventricular function (ejection fraction $<50 \%$ ) in 2 patients. The ejection fraction did not increase over time. Arrhythmias were screened for with Holter monitoring during 5-FU chemotherapy. The frequency of bradycardia and
\end{abstract}

ventricular extrasystoles increased significantly ( $p<$ 0.05 ) during treatment compared to arrhythmias in Holter monitoring 3 months later. Furthermore the Qtc time in the ECG 3 months later was significantly prolonged $(p<0.05)$ compared to baseline values. Conclusions: The incidence of angina pectoris in patients during 5-FU treatment seems higher than previously suspected. As myocardial ischemia can be fatal, attentiveness to these symptoms and immediate treatment are crucial.

Copyright $\odot 2003$ S. Karger AG, Basel

\section{Introduction}

5-Fluorouracil (5-FU), an S-phase-specific, synthetic pyrimidine antimetabolite, is used for the treatment of various malignant diseases. After its introduction as an adjuvant treatment in colorectal cancer more than 10 years ago, 5-FU has been of benefit for thousands of patients treated with curative intent. However, there have always been concerns about 5-FU-related cardiotoxicity. The underlying etiology of this phenomenon remains unexplained. Symptoms such as arrhythmias, hypotension and angina pectoris have been reported since 1975 $[1,2]$. Direct toxic effects on the endothelium of coronary arteries, damage to the myocytes or coronary vasospasms

\section{KARGER}

Fax +41613061234

E-Mail karger@karger.ch

www.karger.com
(C) 2003 S. Karger AG, Basel

0030-2414/03/0652-0108\$19.50/0

Accessible online at:

www. karger.com/ocl
Dr. med. A. Wacker

German Heart Center

Lazarettstrasse 36

DE-80636 München (Germany)

Tel./Fax +4989 12180, E-Mail wacker@dhm.mhn.de 
are hypotheses of mechanisms of 5-FU-associated cardiotoxicity. As we hypothesized a high incidence of 5-FUinduced angina pectoris, we carried out a study of planned surveillance of 102 patients.

\section{Patients and Methods}

102 consecutive and unselected patients treated with 5-FU were analyzed in a planned surveillance study. All patients underwent a 12-lead ECG, echocardiography and radionuclide ventriculography at rest, prior to the initiation of treatment with 5-FU chemotherapy (baseline values). As arrhythmias were the most anticipated side effects of 5-FU, Holter monitoring in all patients was performed during 5-FU infusion. To evaluate long-term cardiotoxicity and as an internal control the same examinations were repeated 3 months from baseline. The primary end point was the incidence and duration of ischemic symptoms during 5-FU infusion. Secondary end points included clinical events, cardiac function and arrhythmias during 5FU infusion and at 3 months from baseline. In 6 out of 19 patients with severe symptoms of angina pectoris a subsequent coronary angiography was performed.

\section{Statistical Analysis}

The study was originally designed to include 102 patients to have statistical power. All data were analyzed with Wilcoxon test; $p$ values lower than 0.05 were considered to indicate statistical significance. All statistical analyses were performed with the use of SPSS software (version 9.0; Chicago). All data are kept at the Technical University of Munich.

\section{Patient Characteristics}

102 patients (70 male and 32 female) participated in the study. The median age was 62 years (range 39-78). A history of preexisting coronary artery disease was found in 12 patients by exploration, of whom myocardial infarction was found in 2 patients and cardiomyopathy was found in 4 patients. The cause of cardiomyopathy is unclear. $17.6 \%$ of all patients were receiving angiotensin-converting enzyme, $13 \% \beta$-blockers, $2 \%$ nitrates and $8 \%$ diuretics as concomitant cardiac medication prior to the enrollment. This medication was continued. $80 \%$ of the patients suffered from a carcinoma of the digestive tract, the remaining $20 \%$ had carcinomas of the head and neck. $68 \%$ of the patients received 5-FU as a monotherapy, whereas $32 \%$ were treated with a combination of chemotherapeutic agents, mainly with cisplatin ( $20 \%$ of the patients). None of the patients receiving cisplatin developed cardiac chest pain. $80 \%$ of all patients received 5-FU $\left(2,600 \mathrm{mg} / \mathrm{m}^{2}\right)$ as a continuous infusion over $24 \mathrm{~h}$, the other $20 \%$ of the patients received bolus $5-\mathrm{FU}\left(400 \mathrm{mg} / \mathrm{m}^{2}\right.$, table 1$)$.

\section{Results}

19 of the 102 patients complained of angina pectoris within $24 \mathrm{~h}$ of the initiation of 5-FU treatment. Angina pectoris was defined as severe anginal pain occurring in low or no workload. Examining the cardiac risk factors of
Table 1. Patient characteristics

\begin{tabular}{|c|c|}
\hline Patients & 102 \\
\hline \multicolumn{2}{|l|}{ Sex } \\
\hline Males & 70 \\
\hline Females & 32 \\
\hline Median age, years & 61.7 \\
\hline \multicolumn{2}{|l|}{ Tumor localization } \\
\hline Digestive tract & 80 \\
\hline Nasopharynx & 22 \\
\hline \multicolumn{2}{|l|}{$5-\mathrm{FU}$ as } \\
\hline Monochemotherapy, \% & 68 \\
\hline Combined regime, $\%$ & 32 \\
\hline 24 -hour continuous infusion, $\%$ & 80 \\
\hline $400-\mathrm{mg} / \mathrm{m}^{2}$ bolus, $\%$ & 20 \\
\hline \multicolumn{2}{|l|}{ Cardiac diseases } \\
\hline Coronary artery disease & 12 \\
\hline Myocardial infarction & 2 \\
\hline Bypass & 2 \\
\hline PTCA & 2 \\
\hline Cardiomyopathy & 4 \\
\hline \multicolumn{2}{|l|}{ Cardiac medication } \\
\hline $\mathrm{ACE}$ & 18 \\
\hline$\beta$-Blocker & 13 \\
\hline Nitrate & 3 \\
\hline Diuretics & 9 \\
\hline ASA & 5 \\
\hline \multicolumn{2}{|c|}{$\begin{array}{l}\text { Cardiac risk factors in patients with angina } \\
\text { pectoris }\end{array}$} \\
\hline Hypertension & 2 \\
\hline Diabetes mellitus & 1 \\
\hline Atrial fibrillation & 1 \\
\hline \multicolumn{2}{|c|}{$\begin{array}{l}\text { PTCA = Percutaneous transluminal cor- } \\
\text { onary angioplasty; ACE = angiotensin-con- } \\
\text { verting enzyme; ASA = acetylsalicylic acid. }\end{array}$} \\
\hline
\end{tabular}

these 19 patients, none had known coronary artery disease, but we found 2 patients who suffered from hypertension and 1 patient who suffered from atrial fibrillation. Non-insulin-dependent diabetes mellitus was present in 1 patient. The 5-FU infusion was stopped when the symptoms were reported. It is possible that an unexpectedly high rate of chest pain was identified because patients were told they were participating in a study looking at cardiac function in patients on 5-FU. But most of these 19 patients had classical ECG changes of myocardial ischemia (ST segment depression, raised ST segment and ventricular extrasystoles) lasting between 2 and $12 \mathrm{~h}$ after the infusion had been stopped. The ECG changes disap- 


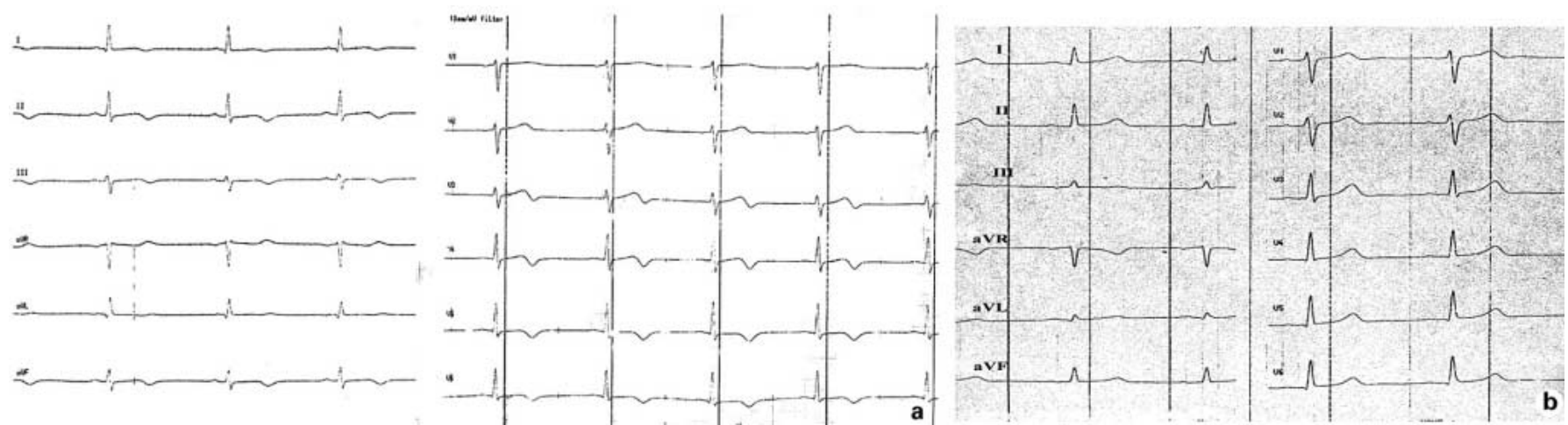

Fig. 1. Patient A. a $12 \mathrm{~h}$ after continuous 5-FU infusion. b $30 \mathrm{~min}$ after stopping the infusion.
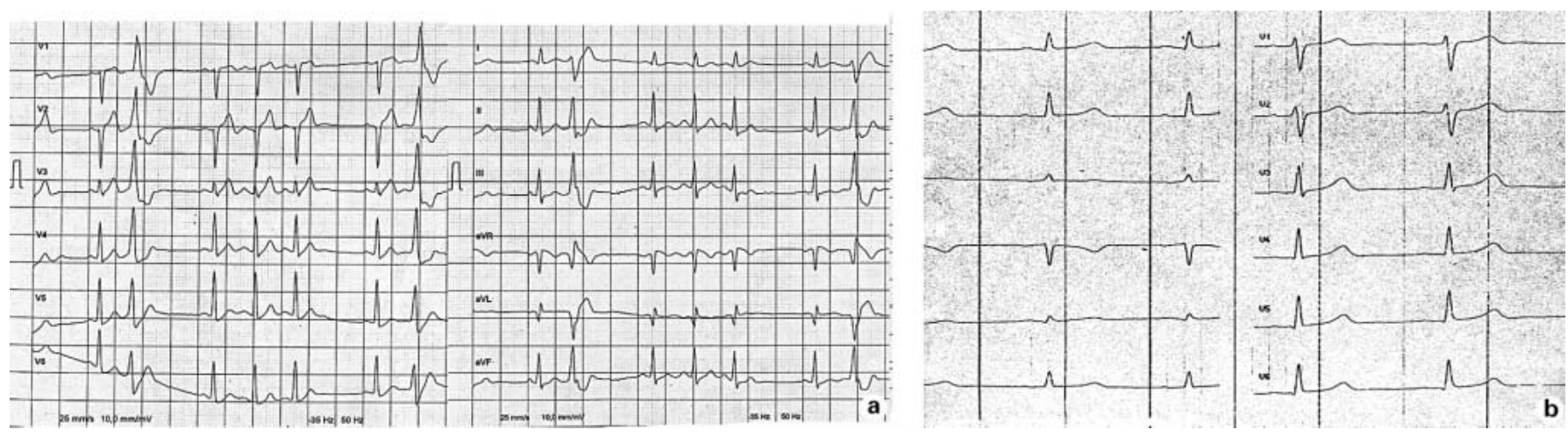

Fig. 2. Patient B. a $2 \mathrm{~h}$ after continuous infusion. b $2 \mathrm{~h}$ after stopping the infusion.
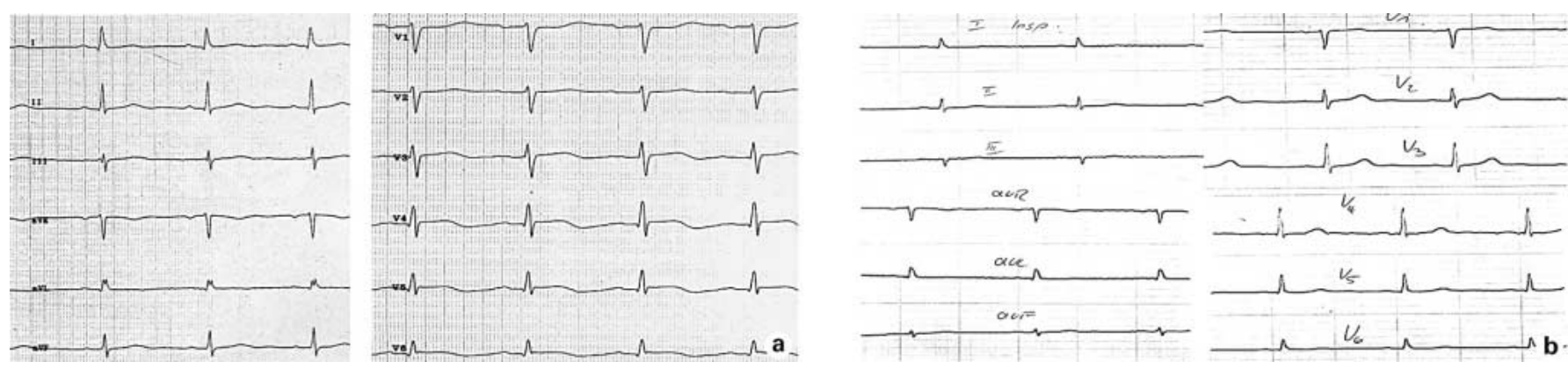

Fig. 3. Patient C. a $22 \mathrm{~h}$ after continuous infusion. b $2 \mathrm{~h}$ after stopping the infusion.

peared concomitant with diminishing symptoms (fig. 13). In 6 out of 19 patients cardiac enzymes were measured, which were initially normal and did not rise over 6 h. 6 of the 19 patients had severe symptoms of angina pectoris. A subsequent coronary angiography was performed. None of these patients showed significant coro- nary artery disease, especially no flow-limiting stenosis. 2 patients had low ventricular function $(\mathrm{EF}<50 \%)$ as a sign of acute cardiotoxicity compared to baseline function of the echocardiography 3 months before. The ejection fraction did not increase over time. Symptoms of angina pectoris could be reduced by giving calcium antagonists (dil- 
Table 2. Cardiac parameters

\begin{tabular}{llllll}
\hline & Mean & SD & Minimum & Maximum & $\begin{array}{l}\text { Wilcoxon } \\
\text { rank test }\end{array}$ \\
\hline QTc 1 & 0.3711 & 0.03894 & 0.26 & 0.43 & \\
QTc 2 & 0.3869 & 0.04483 & 0.32 & 0.50 & $\mathrm{p}=0.038$ \\
FS 1 & 38.89 & 3.92 & 32 & 43 & \\
FS 2 & 35.63 & 8.47 & 18 & 43 & $\mathrm{p}=0.774$ \\
LZ VES 1 & 35.88 & 81.39 & 0 & 237 & \\
LZ VES 2 & 13 & 15.64 & 0 & 35 & $\mathrm{p}=0.01$ \\
LZ HF 1 & 63.75 & 12.67 & 52 & 86 & \\
LZ HF 2 & 61.75 & 19.05 & 49 & 90 & $\mathrm{p}=0.003$ \\
\hline
\end{tabular}

tiazem $180 \mathrm{mg} /$ day) and acetylsalicylic acid (100 mg/day) in all 19 patients. Venous hemoglobin concentration in these patients was not lower than $10.2 \mathrm{~g} / \mathrm{dl}$ and the serum potassium level was at least $3.4 \mathrm{mmol} / \mathrm{l}$. There was a tendency that patients receiving 5-FU as a bolus developed more cardiac chest pain compared to those receiving the drug by continuous infusion.

In all 102 patients, the 12-lead ECG showed no differences in PQ intervals, QRS complexes and QT intervals, prior to, during and 3 months from baseline. Echocardiography and radionuclide ventriculography in all 102 patients 3 months later remained unchanged compared to baseline values (FS mean before: 38.8; FS mean after 3 months: $35.63 ; \mathrm{p}=0.774)$. The QTc time in the ECG at rest was significantly $(\mathrm{p}<0.05)$ longer 3 months from baseline (QTc mean before: mean 0.3711, minimum: 0.26, maximum 0.43, standard deviation 0.038; QTc after 3 months: mean 0.38 , minimum: 0.32 , maximum: 0.5 , standard deviation 0.044; Wilcoxon rank test: $\mathrm{p}=$ 0.0038 ). Significantly higher frequency of bradycardia and ventricular extrasystoles during 5-FU infusion was observed in Holter monitoring (mean VES 35.88 versus $13 ; \mathrm{p}<0.05$, table 2 ). These arrhythmias were not reproduced 3 months from baseline in Holter monitoring.

\section{Discussion}

5-FU cardiotoxicity has not been fully understood and its frequency seems to be underestimated according to our results [3]. With the development and widespread application of oral bioavailable 5-FU prodrugs (i.e. capecitabine) cardiotoxicity will increasingly become an important issue $[4,5]$. Therefore physicians treating patients with 5-FU should be highly attentive to these symptoms and antivasospastic treatment (such as calcium antagonists) should be administered promptly [6]. Since the symptoms of angina pectoris of all 19 patients were reversible and there were no signs of myocardial damage and since the symptoms could be relieved by calcium antagonists, our hypothesis for the mechanism of 5-FU cardiotoxicity is vasospasm. This hypothesis is supported by 6 normal angiographies in severely symptomatic patients and a recent finding of coronary artery vasospasms as a cause of effort-related myocardial ischemia during low-dose continuous infusion of 5-FU [7].

The next question that arises is whether there are underlying risk factors such as hypertension leading to endothelial dysfunction which could induce vasoconstriction. The endothelium modulates several other vascular functions including platelet aggregation, monocyte adhesion and migration [8]. Endothelial dysfunction could be a transient risk factor that might promote vasoconstriction [9]. A further prospective trial stratification for hypertensive patients is necessary, and optionally blood levels of endothelin-1 should be measured. In addition a possible correlation of 5-FU peak blood levels and symptomatic episodes is of interest.

The underlying mechanism for 5-FU-induced arrhythmias is still unknown. We found a significantly higher QTc time in patients treated with 5-FU and even significantly higher frequency of bradycardias and ventricular extrasystoles. Disturbance of cardiac rhythm could not be monitored, since the number of patients in our study was too small. We hypothesized that intra- and extracellular potassium balance might be disturbed. To evaluate this hypothesis further investigations are necessary.

\section{Conclusions}

Even if the etiology of 5-FU cardiotoxicity is not solved the most probable hypothesis in our opinion is a reversible vasospasm. Antivasospastic therapy therefore 
is the first approach to reduce vasospasm. Careful surveillance and monitoring beyond the half-life of 5-FU is mandatory as symptoms and ECG changes last up to $12 \mathrm{~h}$ after discontinuation of 5-FU. Clinical and ECG manifestation of angina should prompt drug discontinuation. Whether reexposure to the triggering drug is safe remains to be answered in another controlled trial.

\section{Acknowledgments}

We thank Prof. Dr. Peschel, PD Dr. H. Bernhard, Dr. C. v. Schilling, Dr. F. Lordick, III. Medizinische Klinik, Dr. J. Pache, I. Medizinische Klinik, Prof. Dr. Fink, Chirurgische Klinik, Prof. Dr. Molls, Strahlentherapie, and Dipl.-Math. R. Busch, Institut für Medizinische Statistik und Biometrie, Technische Universität München for supporting the study.

\section{References}

1 Aziz SA, Tramboo NA, Mohi-du-Din K: Supraventricular arrhythmia: A complication of 5-fluorouracil. Clin Oncol 1998;10:377-378.

2 Freemann NJ, Costanza ME: 5-Fluorouracilassociated cardiotoxicity. Cancer 1988;61:3645.

3 Heidelberger C, Chauduri NK, Danneberg P: Fluorinated pyrimidines, a new class of tumorinhibitory compounds. Nature 1957;4561: 663-666.
4 Bertolini A, Flumano M, Fusco O: Acute cardiotoxicity during capecitabine treatment: A case report. Tumori 2001;87:200-206.

5 Schnetzler B, Popova N, Collao Lamb L: Coronary spasm induced by capecitabine. Ann Oncol 2001;12:723-725.

6 Oleksowicz L, Bruckner HW: Prophylaxis of 5fluorouracil-induced coronary vasospasm with calcium channel blockers. Am J Med 1988;85: $750-751$.
7 Lestuzzi C, Viel E, Picano E: Coronary vasospasm as a cause of effort-related myocardial ischaemia during two-dose chronic continuous infusion of 5-fluorouracil. Am J Med 2001;111: 316-318.

8 Panza AJ: High normal blood pressure: More 'high than normal'. N Engl J Med 2001;345: 1337-1339.

9 Vallance P, Collier J, Bhaggat K: Infection, inflammation and infarction: Does acute endothelial dysfunction provide a link? Lancet 1997;349:1391-1392.

\section{Erratum}

In 'Role of Gemcitabine in the Treatment of Advanced and Metastatic Breast Cancer' (Heinemann, Oncology 2003;64:191-206) an omission occurred in reporting the dosing of gemcitabine in the Global Phase II study of gemcitabine plus paclitaxel vs. paclitaxel alone (table 6, p. 202). The regimen should read Gem 1,250 d1 and d8 plus Pac $175 \mathrm{~d} 1$ vs. Pac 175 d 1 .

Wacker/Lersch/Scherpinski/Reindl/ Seyfarth 